\title{
SPEECH ERRORS PRODUCED BY EFL LEARNERS OF ISLAMIC BOARDING SCHOOL IN TELLING ENGLISH STORY
}

\author{
Agustina Ridho Utami ${ }^{1}$ \\ 1(IAIN Salatiga/agustina.ridhoutami@gmail.com) \\ Noor Malihah ${ }^{2}$ \\ 22(IAIN Salatiga/noormalihah_itah@yahoo.com)
}

\begin{abstract}
The students of Islamic Boarding School Nurul Islam are used to learn spoken English, but they still make some errors when they are speaking. They often produce some speech errors when they are making an English conversation or when they are getting turn to speak in front of the class. This study aims to investigate the existence and the frequency of speech errors especially Silent Pause and Filled Pause produced by the students of Islamic Boarding School Nurul Islam in telling English Story. This research is a descriptive-qualitative with data presented in statistical forms. The object of this research is Speech Errors produced by students in telling English Story. And the respondents are 30 students from the $8^{\text {th }}$ grade of English Tutorial Program in Islamic Boarding School Nurul Islam in the academic year of 2016/2017. This research was conducted by observation. It was to investigate the existence of Silent Pause and Filled Pause produced by the students in telling English story and to investigate the percentages of each speech errors. The findings of the observation in this research show 603 (100\%) speech errors produced by students. Silent pause is $524(87 \%)$ and Filled Pause is 79 (13\%).
\end{abstract}

Keywords:

Speech Errors, Silent Pause, Filled Pause, Storytelling

DOI: $10.19105 /$ ojbs.v12i2.1930

\section{A. Introduction}

Language is a way to communicate with others. Both human and animal have their ways in communicating effectively. But, the most significant difference between a human and an animal is that a human is able to talk while an animal is not. Clark \& Clark explain that communication with language is carried out through two basic human activities: speaking and listening. ${ }^{1} \quad$ These are particularly important to psychologists. They are mental activities that hold clues to the very nature of the human mind. Traxler explains how speech is produced. ${ }^{2} \mathrm{~A}$

\footnotetext{
${ }^{1}$ Herbert H. Clark and Eve V. Clark, Psychology and Language: An Introduction to Psycholinguistics (New York: Harcourt Brace Javanovich, Inc, 1997), 3.

2 Matthew J. Traxler, Introduction to Psycholinguistics: Understanding Language Science (United Kingdom: Wiley-Blackwell, 2012), 38.
} 
theory must describe the mental representations that support the translation between ideas, which are mentally represented in a non-language form, and the mental plans that cause muscles to move. After all, speech requires physical action.

According to Traxler, he states that speech is more complicated than many other physical actions that we perform because speech requires exquisitely tight control over more than 100 muscles moving simultaneously. ${ }^{3}$ And he outlines that speech production requires at least three kinds of mental operations (Conceptualization, Formulation, and Articulation).

A speaker, whether he is still a child or an adult, he/she cannot be fully aware at all when he/she is producing sentences. The speaker sometimes ever forgets some words that he/she will say especially when he/she is speaking up in front of many people. It can cause some speech errors in producing a sentence. Clark \& Clark tell that speech errors are producing an incorrect word when the speakers do not give an ideal delivery (Ideal delivery is when speakers know what they want to say and say it fluently). ${ }^{4}$

Learning English as a foreign language is not a simple thing to do. All foreign languages, such as English, cannot be learned naturally. This is because English is not their first

\footnotetext{
${ }^{3}$ Traxler, 38.

${ }^{4}$ Clark and Clark, Psychology and Language: An Introduction to Psycholinguistics, 261.
}

language. So, there are many differences between English and Indonesia, for examples: grammatical, pronunciation and many others. They become common problem faced by students in learning English, such as oral English.

One of the subjects of speaking skill that is applied in every school is Telling Story. It is not only learned to the students in order that they can pass that subject well but also it is learned to the students in order that they can master in public speaking well. According to Spaulding, there are many reasons why storytelling is important and why it is satisfying. ${ }^{5}$ It is not just for the enjoyment of the occasion but also for civilization in general and for this civilization in a time of major flux. Storytelling is as a form of entertainment representing the past and the many ways of being human that are possible.

Most educational institutions in Indonesia bring Story Telling as one of the branches of English Competition. It is the way to show up students' ability in speaking English and inure them to speak up in the public speaking. Therefore, Indonesian Students can carry out their country to go to the international competition or international event.

Based on an observation that the researcher has conducted in Ma'had Nurul Islam (Islamic Boarding School Nurul Islam), the students of this school

\footnotetext{
5 Amy E. Spaulding, The Art of Storytelling: Telling Truths Through Telling Stories (Lahnan: Scarecrow Press, 2011), 20.
} 
get some English lessons. They do not only learn English in formal school, but they also learn English through some language programs of boarding school (Ma'had). One of the programs is a Language Tutorial Program. In the program, the students study the structure of English (Grammatical English) and practice English in orally. One of practicing model is English storytelling. Although the students of Islamic Boarding School Nurul Islam are used to learn spoken English, they still make some errors when they are speaking. They often produce some speech errors when they are making an English conversation or when they are getting the turn to speak in front of the class. With the new trends of English storytelling in the Indonesian schools, it is, therefore, necessary for the writers to investigate the existence of silent pause and filled pause produced by the students of Islamic Boarding schools Nurul Islam and also to find out how frequently those errors produced.

There have been several works in the literature discussing speech errors. ${ }^{6}$

6 Anna Esposito, Maria Marinaro, and Giulia Palombo, "Children Speech Pauses as Markers of Different Discourse Structures and Utterance Information Content," MIT, 2004, 6; Sharon Goldwater, Dan Jurafsky, and Christopher D. Manning, "Which Words Are Hard to Recognize? Prosodic, Lexical, and Disfluency Factors That Increase Speech Recognition Error Rates," Speech Communication 52, no. 3 (March 1, 2010): 181-200, https://doi.org/10.1016/j.specom.2009.10.001; Rasmus Dall, Mirjam Wester, and Martin Corley, "The Effect of Filled Pauses and Speaking Rate
This research demonstrates new concerns with the same object that is Speech Errors. But this research can be proved its authenticity. This research is conducted in Islamic Boarding School Nurul Islam (Ma'had). The students of Eighth Grade in English Tutorial Program become subjects of this research. The researcher analyses the speech errors produced by the students through English telling story.

According to Traxler human communication occurs most frequently via speech, so understanding speech production (talking) and comprehension lay the foundation for an understanding of human language abilities. ${ }^{7}$ Contemporary theories of speech production take as their starting point the moment in time where the speaker has an idea she wishes to convey. Thus, they focus primarily on how speakers convert ideas into a form that can be expressed in speech, and taken for granted that speakers have ideas to convey.

Speech production is a process of transforming a nonlinguistic conceptual structure representing a communicative intention into a linguistically well-formed utterance. ${ }^{8}$ According to Bock, speech production refers to the cognitive processes engaged in going from mind to

on Speech Comprehension in Natural, Vocoded and Synthetic Speech," INTERSPEECH, 2014, 5.

7 Traxler, Introduction to Psycholinguistics: Understanding Language Science, 3.

$8 \mathrm{H}$. Schriefers and G. Vigliocco, Speech Production (Nijmegen University: Elsevier Ltd., 2001), 255. 
mouth. ${ }^{9}$ Producing connected speech not only entails retrieving words from memory but further entails combining the information into well-formed sentences. ${ }^{10}$

Traxler outlines that speech production requires at least three levels of mental operations (i) Conceptualization where people have to think of something to say, (ii) Formulation, it is when people have something to say, they must figure out a good way to express that idea given the tools that your language provides and (iii) Articulation, where people need to actually move your muscles to make a sound wave that a listener can perceive. ${ }^{11}$

According to Tatham \& Morton, the process of speech production involves consultation of the speaker's knowledge of speech perception, and part of the perceptual process involves consulting the listener's knowledge of speech production. ${ }^{12}$

Speech Perception is a process of involving participation by the listener in interpreting the incoming sound wave. It focuses on the idea that a perceiver is trying to identify what phonological units. $^{13}$

\footnotetext{
9 J. K. Bock, "Sentence Production. From Mind to Mouth," in Handbook of Perception and Cognition, Speech, Language, and Communication, 2nd ed., vol. 11 (San Diego: Academic Press, 1995).

10 Schriefers and Vigliocco, Speech Production, 255.

11 Traxler, Introduction to Psycholinguistics: Understanding Language Science, 30.

${ }^{12}$ Mark Tatham and K. Morton, Guide to Speech Production and Perception (Edinburg: Edinburgh University Press, 2011), 141.

${ }^{13}$ Tatham and Morton, 152.
}

There are many factors which can influence a speaker to come up with a revised utterance plan. The first is the desire to speak more clearly to the listener, or perhaps to speak with what the speaker judges to be a 'better' accent. The second, it is caused by high background noise, and this requires a more careful plan; perhaps the speaker has a cold and knows that speech will be a little rough. ${ }^{14}$ That's why might cause that some speakers made some speech errors.

Garman argues that Error is a condition which can manifest in speech production. He classifies Error into four types. ${ }^{15}$ They are Slip of the tongue, Slip of the ear, Slip of the pen, and Slip of the eye.

Goldrick explains that speech error is a critical source of data on the tacit knowledge that underlies the creative use of the language of the speakers. ${ }^{16}$ While Garman states speech error means saying something not quite as the speaker intended it. ${ }^{17}$ On the other hand, Clark \& Clark tell that speech errors are producing an incorrect word when the speakers do not give an ideal delivery (Ideal delivery is when speakers know what they want to say and say it fluently). ${ }^{18}$

\footnotetext{
${ }^{14}$ Tatham and Morton, 142-43.

${ }^{15}$ Michael Garman, Psycholinguistics (Cambridge: Cambridge University Press, 1990), 151.

${ }^{16}$ M. Goldrick, Speech Errors and Phonological Theory (Northwestern: Northwestern University Press, 2016), 2.

${ }^{17}$ Garman, Psycholinguistics, 151.

${ }^{18}$ Clark and Clark, Psychology and Language: An Introduction to Psycholinguistics, 261.
} 
Garman explains that "Slip of the Tongue" as one of types error in general. Different from Garman, ${ }^{19}$ Clack \& Clark explain that "Slip of the Tongue" is one of the types of Speech Errors. ${ }^{20}$

There are many types of Speech Error according to some experts. But, in this research, the researcher only focuses on "Silent Pause" and "Filled Pause" based on Clark \& Clark. ${ }^{21}$ They tell that the most common disruptions in executing a sentence (an ideal delivery) are the silent pause and filled pause. Silent pause is a period of no spoken words, while filled pause is a gap filled by "ah, er, mm or the like". ${ }^{22}$

The object of this research is Speech Errors produced by students in telling English Story. Spaulding defines story-telling as a form of entertainment representing the past and the many ways of being human that are possible. It is very. ${ }^{23}$ Much exist in fashion right now. It is both good and bad. Good because it is getting attention. And bad because it is being experimented by people who do not understand or respect its power. ${ }^{24}$

Spaulding contends that stories can exhibit joy just by being fun or by being meaningful in a way that makes the listener satisfied, although if the story

\footnotetext{
${ }^{19}$ Garman, Psycholinguistics, 151.

${ }^{20}$ Clark and Clark, Psychology and Language: An Introduction to Psycholinguistics, 263.

${ }^{21}$ Clark and Clark, Psychology and Language: An Introduction to Psycholinguistics.

${ }^{22}$ Clark and Clark, 262.

${ }^{23}$ Spaulding, The Art of Storytelling, 20.

${ }^{24}$ Spaulding, 4.
}

is not a happy one. ${ }^{25}$ The joy does not only come from the story, but it comes also from connecting with others while sharing the story. It does not matter whether you are "sharing it out" by telling it or "sharing it in" by hearing the teller's words and creating it in your own mind.

Samantaray identify that there are eight certain characteristics of storytelling, including (i) how it evoke the students' imagination and interest in learning languages, (ii) how it build the vocabulary and comprehension as well as story sequencing, (iii) how it improves listening and speaking skills, (iv) how it creates an interactive and co-operative process, ( $v$ ) how it becomes an enjoyable means of learning and practicing skills and verbal expressions, (vi) how it helps listeners to remember, (vii) how it makes used of the language convention to make the study vivid, and (viii) how to stimulate the listeners forget their misery. ${ }^{26}$

Spaulding explains that story has some types, they areFolklore, Folk Tale, Wonder Tale, Pourquoi Tale, Myth, Legend, Fable, Parable, Ballad, Hero Tale, Epic, Modern Fantasy, Droll. ${ }^{27}$

Samantaray outlines the functions of storytelling as follows (i) to improve listening and speaking skills, (ii) to demonstrate understanding of rhetorical situations, to exchange information and

\footnotetext{
${ }^{25}$ Spaulding, 13.

26 Pravamayee Samantaray B Ed, "Use of Story Telling Method to Develop Spoken English Skill," International Journal of Language \& Linguistics 1, no. 1 (2014): 41.

${ }^{27}$ Spaulding, The Art of Storytelling, 36-39.
} 
ideas, (iv) to contribute in brainstorming exercise, (v) to develop active listening skills, (vi) to develop confidence in speaking, (vii) to select appropriate expressions for a particular situation and audience, and (ix) to reduce students' inhibition. $^{28}$

\section{B. Method}

This research is descriptivequalitative in nature with data analyzing presented in statistical forms. The object of this research is speech errors produced by the $8^{\text {th }}$-grade students of English Tutorial Program in Islamic Boarding School Nurul Islam Tengaran (Ma'had Nurul Islam) focusing on two types of speech errors, those are Silent Pause and Filled pause. The respondents of this research are 30 students of English Tutorial Program in Islamic Boarding School Nurul Islam Tengaran (Ma'had Nurul Islam) in the academic year of 2016/2017 selected using purposive sampling. The data were collected through observation, video recording and taking a note and taking pictures techniques.

Once the data from video recording were collected, they are analyzed using these steps: (i) transcribing, (ii) identifying of Speech Errors, (iii) classifying Speech Errors, (iv) coding data using // for Silent Pause (SPs) and,..., for Filled Pause (FPs).

${ }^{28}$ Ed, "Use of Story Telling Method to Develop Spoken English Skill," 44.

\section{Results}

Based on the research that had been conducted by the researcher, the researcher collected speech errors produced by 30 students. There are 12 students produced silent pauses, 1 student produced filled pause and 17 students produced both silent pauses and filled pauses. The number of speech errors that the students had produced is 603 pauses. They consisted of 524 silent pauses and 79 filled pauses. The data findings are listed in Table 1.

Table.1

The Distribution of Silent Pause and Filled Pause

\begin{tabular}{|c|l|c|c|}
\hline No. & $\begin{array}{c}\text { Type of } \\
\text { Speech } \\
\text { Errors }\end{array}$ & $\begin{array}{c}\text { N of } \\
\text { Speech } \\
\text { Errors }\end{array}$ & Percentage \\
\hline 1. & $\begin{array}{l}\text { Silent } \\
\text { Pause }\end{array}$ & 520 & $87 \%$ \\
\hline 2. & $\begin{array}{l}\text { Filled } \\
\text { Pause }\end{array}$ & 79 & $13 \%$ \\
\hline \multicolumn{2}{|c|}{ Total } & $\mathbf{6 0 3}$ & $\mathbf{1 0 0 \%}$ \\
\hline
\end{tabular}

Table 1 shows the distribution of silent pause and filled pause produced by the students of Islamic Boarding School Nurul Islam in the telling English story in English Tutorial Program. The frequency of Silent Pause is $87 \%$ and Filled pause is $13 \%$. It shows that the frequency of Silent Pause is higher than the frequency of Filled Pause. The writers predict that the high frequency of silent pause is because of the storytelling activity (see Clark and 
Clark). ${ }^{29}$ As Samantaray has proposed that one of the characteristics of storytelling is to build the students' imagination. Thus to imagine, it is common for the speaker to think about what they imagine by having no speech at all. The results are silent pauses. ${ }^{30}$ Examples of Silent Pause are demonstrated in (1), (2) and (3), while examples of Fiiled Pause are shown in (4) and (5).

\section{Examples of Silent Pause}

a. He found a huge teak // before...

b. A huge teak // what wood but...

c. It was going to be used the // great mosque Delik, Kalipancur village.

d. ... // there were co there were four monkeys come to him.

e. They said // those monkeys...

f. The great leader // proposedly...

g. The main pillar of // of Demak...

The speaker who produced Silent Pause, spoke fluently in the beginning of her speaking during the discussion. However, by the end of her turn to speak, she produced errors.

\section{Examples of Silent Pause}

a. ... and // and then...

b. ... and then // I will...

c. After hunting // Sangkuriang...

d. Sangkuriang // Sangkuriang began desperate...

${ }^{29}$ Clark and Clark, Psychology and Language: An Introduction to Psycholinguistics.

${ }^{30} \mathrm{Ed}$, "Use of Story Telling Method to Develop Spoken English Skill." e. That was not deer but // but Tumang.

f. ...// she was very angry and...

g. She was very angry and // she was...

h. Many // some years ago...

i. Some years ago // some years ago...

j. Some years ago // Sangkuriang arrived at a village.

k. ... Sangkuriang // had to make in one night.

I. ... // Dayang Sumbi had to stop it.

$\mathrm{m}$.... // Sangkuriang was very angry and...

n. And kicked the boat // and now...

o. That place // was called the mountain of Tangkuban Perahu in Bandung

The speaker in examples (2) produced Silent error earlier than the one produced examples (1). She started to produce errors in the middle of her speaking.

\section{Examples of Silent Pause}

a. ... Sunan who // who was very honest.

b. ... // One day, he arrived village in a village.

c. ... // Sunan Kalijaga didn't say his real name...

d. $\ldots$ and he asked for $/ / \ldots$

e. ...// he ask for a job.

f. $\ldots / /$ the chief's wife said...

g. The chief's wife said // that he could help...

h. He could help to // cut grass for horses. 
i. ... // Sunan Kalijaga liked to live simple.

j. The // chief was very surprised.

k. ... // then he decided to follow Sunan lesson.

I. To follow Sunan lesson // he had to leave...

m. ... he had to leave // all properties...

n. ... all properties // but his wife...

o. ... // So, his wife brought all jewelry...

p. ... // when they were taking a rest...

q. When they were taking a rest // in a village...

r. ... Sun... Sunan Kalijaga said // that...

s. ... that // this place...

t. ... this place // would...

u. ... would // be busy and full of people.

v. $\ldots / /$ he gave the place a name.

w. The named was // Salatiga.

$x$. Because, in this place // there were three wrong people.

y. ... and robber // who like to...

z. ... who like to collect // properties.

aa. And now, the // place is called Salatiga.

The speaker of examples (3) produced errors so frequently along her speaking from the beginning to the end. Let us turn to look at the examples of filled pause from the data in examples (4), (5) and (6).

\section{Examples of Filled Pause}

a. the ,eh, I want tell you story...

b. I want tell you story ,ee, The Origin of Surabaya.

c. So ,ee, and the...

d. and the, ee, the border was the sandy sore.

e. They never, ee, they would never battle afresh.

f. Some, ee, there was not much nourishment in the sea.

g. They fought a fresh, ee, they fought afresh and...

h. Baya was happy, ee, and the last I say ...

In the beginning of her speaking, speaker started to produce errors. Next, in the middle, speaker kept producing errors, but at the end she spoke fluently. The writers assumed that the disappearance of the errors are because the speaker successfully reduced her anxiety and became more confident than the beginning of her speaking. So she handled her speaking well and there is no space for errors.

\section{Examples of Filled Pause}

a. ..., em, to choose...

b. ..., ee, the winner would be...

c. The contestant, ee, began to fight and...

d. $\ldots$, ee, a great number...

e. People ,ee, they believe that...

f. ... that Nyale is, ee, Princess Mandalika hair.

The speaker of examples (5) produced filled pause in the middle of 
her speaking and continued until the end. This might be because the speaker lacked his idea or vocabularies in arranging the story. Also, it is possible that actually the speaker just memorized what he would tell in the story telling. Thus he worked hard to memorize what he had to tell.

\section{Examples of Filled Pause}

a. ...,em, to choose...

b. $\ldots$, ee,the winner would be...

c. The contestant, ee, began to fight and...

d. ...,ee, a great number...

e. People ,ee, they believe that...

f. ... that Nyale is ,ee, Princess Mandalika hair.

The speaker of examples (6) is a funny student. However, he got a problem in the beginning of his speaking that he started to produce filled pause. But in the middle of her story, he did not experience any problem in arranging to tell the stories. However, by the end of his speaking, he worked hard to finalize his story and he produced those filled pauses.

What is interesting to look at is that among the 30 students who became the respondents, not all of them produced both silent pause and filled pause. But all of them produced either filled pause or silent pause. Only one respondent did not produced silent pause and eleven respondents produced silent pause only.
The rest of them produced both errors. However, as the writers have reported in the previous section, silent pause is produced almost six times more frequently that filled pause. The assumption fits to what Clark \& Clark have argued that telling stories are likely to increase silent pause, because the speakers are being more careful in selecting their words. ${ }^{31}$ On the other hand, the speaker will produce more filled pause in dialogue than monologue.

Therefore, in this research, the writers had proved that in the telling English story (or monologue), the students produced silent pause in higher frequency than filled pauses, this finding fits to what Clark \& Clark have argued.

The findings of this research give an implication to language teaching especially on how to produce storytelling. Based on the characteristics of storytelling proposed by Samantaray, ${ }^{32}$ teachers of EFL students should be able to select interesting topics to tell. Besides, it is also necessary for teachers to determine appropriate methods and techniques to drill the students' vocabularies. Otherwise, students cannot do the storytelling fluently only because they get difficulty in imagining the topic given. Then, students also experience problems in preparing and selecting the vocabularies they should use.

\footnotetext{
${ }^{31}$ Clark and Clark, Psychology and Language: An Introduction to Psycholinguistics.

${ }^{32}$ Ed, "Use of Story Telling Method to Develop Spoken English Skill."
} 


\section{Conclusion}

Silent Pause and Filled Pause are produced by the $8^{\text {th }}$-grade students of English Tutorial Program in Islamic Boarding School Nurul Islam (Ma'had Nurul Islam) in telling English Story.

Based on the data of 30 students, total speech errors are 603 times. The numbers of Silent Pauses are 524 pauses, whereas the numbers of Filled Pauses are 79 pauses. Silent Pause is higher than Filled Pause. The percentage of Silent Pause is $87 \%$ and the percentage of Filled Pause is $13 \%$.

\section{References}

Bock, J. K. "Sentence Production. From Mind to Mouth." In Handbook of Perception and Cognition, Speech, Language, and Communication, 2nd ed. Vol. 11. San Diego: Academic Press, 1995.

Clark, Herbert H., and Eve V. Clark. Psychology and Language: An Introduction to Psycholinguistics. New York: Harcourt Brace Javanovich, Inc, 1997.

Dall, Rasmus, Mirjam Wester, and Martin Corley. "The Effect of Filled Pauses and Speaking Rate on Speech Comprehension in Natural, Vocoded and Synthetic Speech." INTERSPEECH, 2014, 5.

Ed, Pravamayee Samantaray B. "Use of Story Telling Method to Develop Spoken English Skill." International Journal of
Language \& Linguistics 1 , no. 1 (2014): 5.

Esposito, Anna, Maria Marinaro, and Giulia Palombo. "Children Speech Pauses as Markers of Different Discourse Structures and Utterance Information Content." MIT, 2004, 6.

Garman, Michael. Psycholinguistics. Cambridge: Cambridge University Press, 1990.

Goldrick, M. Speech Errors and Phonological Theory. Northwestern: Northwestern University Press, 2016.

Goldwater, Sharon, Dan Jurafsky, and Christopher D. Manning. "Which Words Are Hard to Recognize? Prosodic, Lexical, and Disfluency Factors That Increase Speech Recognition Error Rates." Speech Communication 52, no. 3 (March 1, 2010): 181-200. https://doi.org/10.1016/j.specom. 2009.10.001.

Schriefers, H., and G. Vigliocco. Speech Production. Nijmejen University: Elsevier Ltd., 2001.

Spaulding, Amy E. The Art of Storytelling: Telling Truths Through Telling Stories. Lahnan: Scarecrow Press, 2011.

Tatham, Mark, and K. Morton. Guide to Speech Production and Perception. Edinburg: Edinburgh University Press, 2011.

Traxler, Matthew J. Introduction to Psycholinguistics: Understanding Language Science. United Kingdom: Wiley-Blackwell, 2012. 